\title{
A study of effect of dye structure on polyelectrolyte induced metachromasy
}

\author{
Nandini Ratnakar \\ Department of Chemistry, MITE, Moodabidri-574 226 (DK), Karnataka, India \\ Email address \\ nandinifalnir@yahoo.com
}

To cite this article:

Nandini Ratnakar. A Study of Effect of Dye Structure on Polyelectrolyte Induced Metachromasy. Science Journal of Chemistry.

Special Issue: Polyelectrolytes \& Dyes. Vol. 2, No. 6-2, 2014, pp. 1-7. doi: 10.11648/j.sjc.s.2014020602.11

\begin{abstract}
The interaction of two cationic dyes, namely, Azure B (AB) and Pinacyanol chloride (Pcyn) with an anionic polyelectrolyte, namely, sodium carrageenate (NaCar) has been investigated by Spectrophotometric method. The polymer induced metachromasy in the dyes resulting in the shift of the absorption maxima of the dyes towards shorter wavelengths. The stability of the complexes formed between Azure B and sodium carrageenate was found to be lesser than that formed between Pinacyanol chloride and sodium carrageenate. This fact was further confirmed by reversal studies using alcohols, urea surfactants and electrolytes. The interaction parameters revealed that binding between Azure B and sodium carrageenate was mainly due to electrostatic interaction while that between Pinacyanol chloride and carrageenate is found to involve both electrostatic and hydrophobic forces. The effect of the structure of the dye and its relation to metachromasy has been discussed.
\end{abstract}

Keywords: Cationic Dyes, Metachromasy, Sodium Carrageenate, Dye Structure, Aggregation

\section{Introduction}

Metachromasy is a well-known phenomenon in the case of dye-polymer interactions and is generally found in the case of aggregation of cationic dyes on anionicpolymers [1-4]. Metachromasy is related to the interaction of cationic dyes with polyanions where a single individual compound is formed by the interaction of the dye cation and the chromotrope polyanionic polymer. Several physiochemical parameters such as molecular weight of each repeating unit, stoichiometry of the dye-polymer complex, binding constant, and other related thermodynamic parameters like free energy, enthalpy, and entropy changes can be evaluated using polymer-dye interactions.Biological activity of macromolecules depends on its tertiary conformation. Conformation of the polyanions controls the induction of metachromasy of aqueous dye solution. Although there are several reports on metachromasy of various classes of acidic polysaccharides and different synthetic polyanions $[5,6]$. Cyanine dyes, which are cationic in nature, have widely been used to probe biological systems such as helical structure of DNA, tertiary conformation of bacterial polysaccharides and other polymers.

As these dye having high light absorptivity, they can be used as optical probes in studying membranes, micelles and other host systems [7-10]. Studies on polymer-surfactant interaction in aqueous solution have been attracting widespread attention due to multiple practical uses in biology [11-14] .Such studies are also assumed to be important as the mixed systems/aggregates can give rise to advanced functions that are unobtainable from single component [15].Several physicochemical properties of macromolecule surfactants are quite relevant in this context. Formulation procedures based on suitable mixture may have been appealing applications [16-18] has been noted that oppositely charged surfactant binds to polymer surfaces through both electrostatic and hydrophobic interaction [19]. Different techniques for their isolation and stability determination of metachromatic complexes have been reported in literature [20]. The phenomena of reversal of metachromasy by addition of urea, alcohol neutral electrolytes [21] and also by increasing the temperature of the system may be used to determine the stability of the metachromatic compounds. The nature of dye-polymer interaction in the metachromatic complex formation and also the conditions for the interaction between the cationic dye and the anionic site of the macromolecules has been studied by determining the thermodynamic parameters of the interaction [22]. The 
interaction between polyelectrolytes and oppositely charged surfactants [23, 24] has been investigated due to its importance in both fundamental and applied fields. [25]. Comprehensive studies of a variety of cationic surfactants with anionicpolyelectrolytes, have been reported [26-32]. Cationic dyes that interacted with Heparin mostly fell in the Thiazine group such as MethyleneBlue [33-35]. Azure A [36, 37], Azure B [38, 39]. Hence the objective of the present study is to compare the extent of metachromasy induced by sodium carrageenate in the cationic dyes Azure B and Pinacyanol chloride and to evaluate the thermodynamic parameters of interaction and to study the extent of reversal by using alcohols, urea, surfactants and electrolytes which is an indirect evidence for the stability of the metachromatic complex formed. The effect of dye structure on metachromasy has also been discussed.

\section{Materials \& Methods}

\subsection{Apparatus}

The spectral measurements were carried out using Shimadzu UV-2500 Spectrophotometer using a $1 \mathrm{~cm}$ quartz cuvette.

\subsection{Reagents}

Azure B (AB) was obtained from (Hi Media, Germany) and used as received.Pinacyanol chloride (Pcyn), was obtained from (Acros Media, Germany). sodiumcarrageenate (NaCar) (Loba Chemie, India) were used without further purification; Methanol, (MeOH) ethanol(EtOH) and 2Propanol (PrOH) (Merck, India) were distilled before use. Urea, sodium chloride and potassium chloride were obtained from (Merck, India). Sodium laurylsulphate and sodium dodecylbenzenesulphonate (Lobachemie, India) were obtained from (Loba Chemie, India) .

\section{Methods}

\subsection{Determination of Stoichiometry of Polymer-Dye Complex}

Increasing amounts of polymer solution $\left(0.0-\right.$ to $\left.5 \times 10^{-3} \mathrm{M}\right)$ were added to a fixed volume of dye solution $\left(0.5 \mathrm{ml}, 1 \times 10^{-3} \mathrm{M}\right)$ in case of Azure $\mathrm{B}$ and $\left(0.5 \mathrm{ml}, 1 \times 10^{-3} \mathrm{M}\right)$ of dye to increasing amount of polymer solution $\left(0.0-2.5 \times 10^{-3} \mathrm{M}\right)$ in case of pinacyanol chloride in different sets of experiments and the total volume was made up to $10 \mathrm{ml}$ by adding distilled water in each case. The absorbances were measured at $645 \mathrm{~nm}$ and $545 \mathrm{~nm}$ in case of AB-Car and at $600 \mathrm{~nm}$ and $486 \mathrm{~nm}$ in case of Pcyn-Car complex.

\subsection{Study of Reversal of Metachromasy Using Alcohols and Urea}

For measurements of the reversal of metachromasy, solutions containing polymer and dye in the ratio 2.0:1.0 were made containing different amount of alcohol. The total volume was maintained at $10 \mathrm{ml}$ in each case. The absorbances were measured at $645 \mathrm{~nm}$ and $545 \mathrm{~nm}$ in case of $\mathrm{AB}-\mathrm{NaCar}$ and at $600 \mathrm{~nm}$ and $486 \mathrm{~nm}$ in case of Pcyn-NaCar. Similarly, polymer-dye solutions containing different amounts of urea $(1-8 \mathrm{M})$ were made and the absorbances were measured at $645 \mathrm{~nm}$ and at $545 \mathrm{~nm}$ in case of AB-NaCar complex and at $600 \mathrm{~nm}$ and at $486 \mathrm{~nm}$ in case of Pcyn-NaCar complex.

\subsection{Study of Reversal of Metachromasy Using Surfactants and Electrolytes}

For measurements of the reversal of metachromasy, solutions containing polymer and dye in the ratio 2.0:1.0 were made containing different amount of surfactants or $\left(1 \times 10^{-7} \mathrm{M}-1 \times 10^{-2} \mathrm{M}\right)$ were made in case of $\mathrm{AB}-\mathrm{NaCar}$ and $\left(1 \times 10^{-6} \mathrm{M}-0.1 \mathrm{M}\right)$ in case of Pcyn-NaCar The total volume was maintained at $10 \mathrm{ml}$ in each case. The absorbances were measured at $645 \mathrm{~nm}$ and $545 \mathrm{~nm}$ in case of AB-NaCar and at $600 \mathrm{~nm}$ and $486 \mathrm{~nm}$ in case of Pcyn-NaCar. Similarly, polymer-dye solutions containing different amounts of electrolytes $\left(1 \times 10^{-6} \mathrm{M}-0.1 \mathrm{M}\right)$ in case of AB-NaCar and (1x10 $\left.{ }^{7} \mathrm{M}-1 \times 10^{-2} \mathrm{M}\right)$ in case Pcyn-NaCar were made and the absorbances were measured at $645 \mathrm{~nm}$ and at $545 \mathrm{~nm}$ in case of AB-NaCar complex and at $600 \mathrm{~nm}$ and at $486 \mathrm{~nm}$ in case of Pcyn-NaCar complex. A plot of absorbance at $545 \mathrm{~nm}$ in case of Azure B and at $600 \mathrm{~nm}$ in case of Pinacyanol chloride Vs molar concentration of surfactants or electrolytes were made to determine the concentration of surfactants and electrolytes needed for complete reversal of metachromasy.

\subsection{Determination of Thermodynamic Parameters}

The thermodynamic parameters were determined by measuring the absorbances of the pure dye solution at the respective monomeric band and metachromatic band in the temperature range $\left(36^{\circ} \mathrm{C}-54^{\circ} \mathrm{C}\right)$. The above experiments were repeated in presence of the polymers at various polymer-dye ratios $(2,5,8$ and 10).

\section{Results \& Discussion}

The absorption spectra of Azure B and Pinacyanol chloride shows an absorption maximum at $645 \mathrm{~nm}$ in case of Azure B and $600 \mathrm{~nm}$ in case of Pinacyanol chloride indicating the presence of a monomeric dye species in the concentration range studied. On adding increasing amounts of polymer solution the absorption maxima shifts to $545 \mathrm{~nm}$ in case of $\mathrm{AB}-\mathrm{NaCar}$ and at $486 \mathrm{~nm}$ in case of Pcyn-NaCar complex. The blue shifted band is attributed to the stacking of the dye molecules on the polymer backbone and this reflects high degree of co-operativity in binding [40].Appearance of multiple banded spectra proposed that the polymer might have a random coil structure in solution. Whereas at higher concentration of the polymer almost a single banded spectrum was observed due to possible change from random coil to helical form [41].The absorption spectra at various P/D ratios are shown in (Fig.1 and Fig.2) respectively. 


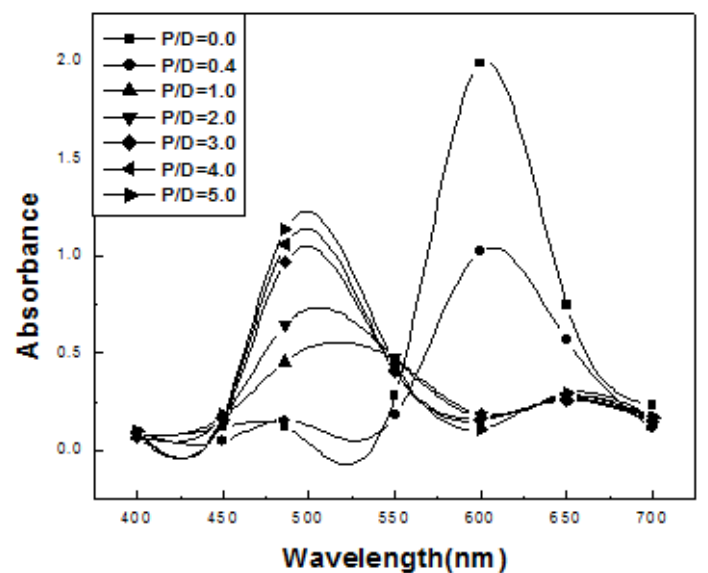

Figure 1. Absorption spectrum of AB-NaCar at various $P / D$ ratios

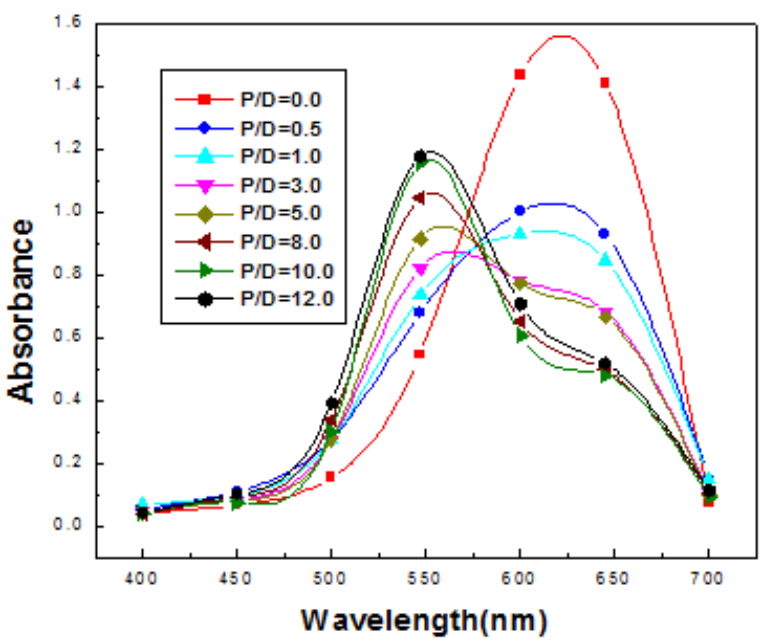

Figure 2. Absorption spectra of Pcyn-NaCarcomplex at various $P / D$ ratios

\subsection{Determination of Stoichiometry}

To determine the stoichiometry of the polymer-dye complex, a plot of $\mathrm{A}_{545} / \mathrm{A}_{645}$ versus the polymer/dye ratio was made for AB-NaCar system. A similar procedure was repeated with Pcyn- NaCar complex also. The stoichiometry of AB-NaCar complex was found 1: 2 which indicates that the binding is at alternate anionic sites. This indicates that every potential anionic site of the polyanion was associated with the dye cation and aggregation of such dye molecules was expected to lead to the formation of a card pack stacking of the individual monomers on the surface of the polyanion so that the allowed transition produces a blue-shifted metachromasy [42].The results were in good agreement with the reported values for interaction of similar dyes withpolyanions[43] .While in case of Pcyn-NaCar complex the stoichiometry is $1: 3$ and the binding is at alternate anionic sites. This indicates that there is lesser overcrowding and more aggregation of the bound dyes on the polymer chain in the latter case than in the former case. Similar results were reported in case of binding of Pinacyanol chloride on poly(methacrylicacid) \&poly(styrenesulfonate) systems [44].The stoichiometry results are obtained by plotting
$\mathrm{A}_{645} / \mathrm{A}_{545}$ or $\mathrm{A}_{600} / \mathrm{A}_{486} \mathrm{Vs} \mathrm{P} / \mathrm{D}$ ratio in each case.The results are shown in (Fig. 3 and Fig. 4) respectively.

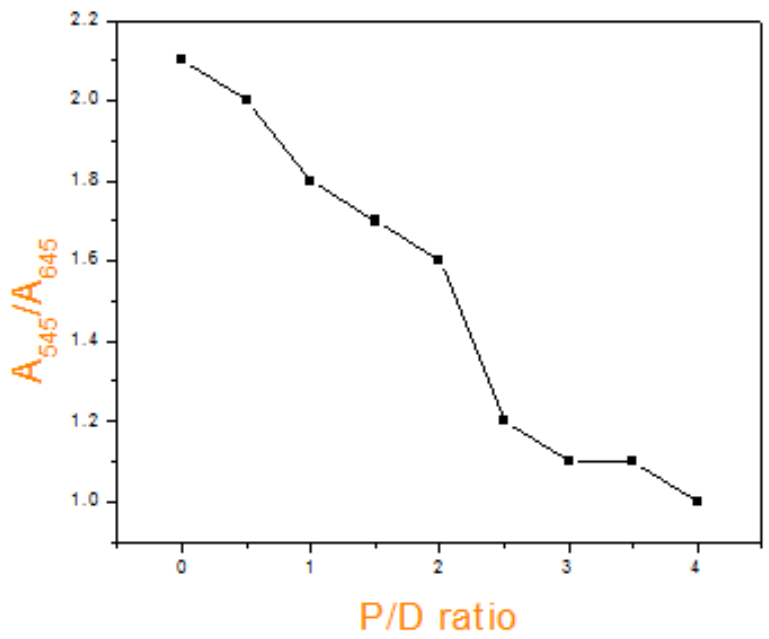

Figure 3. Stoichiometry of AB-NaCar complex

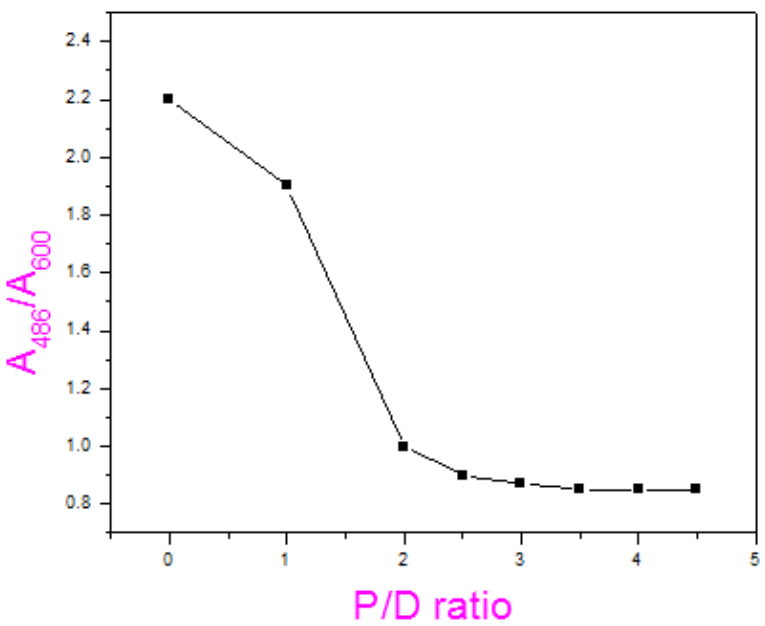

Figure 4. Stoichiometry of Pcyn-NaCar complex

\subsection{Reversal of Metachromasy Using Alcohols and Urea}

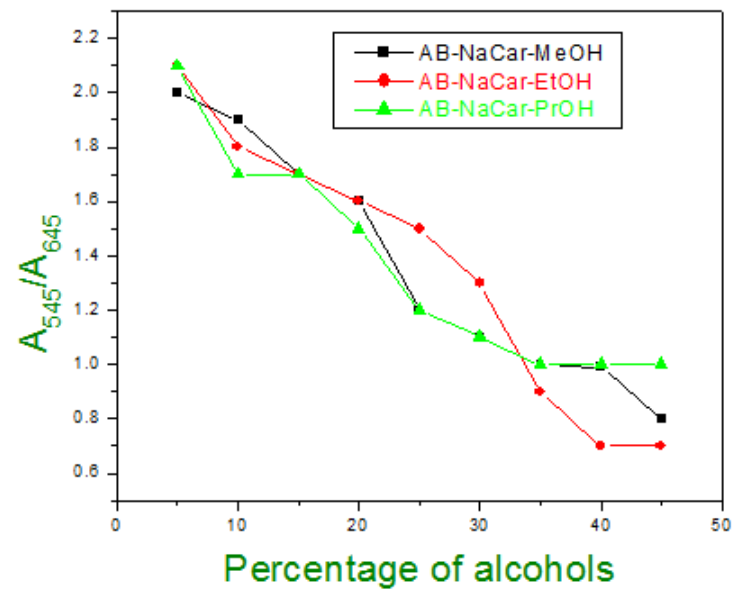

Figure 5. Reversal of metachromasy on addition of alcohols(AB-NaCar) 


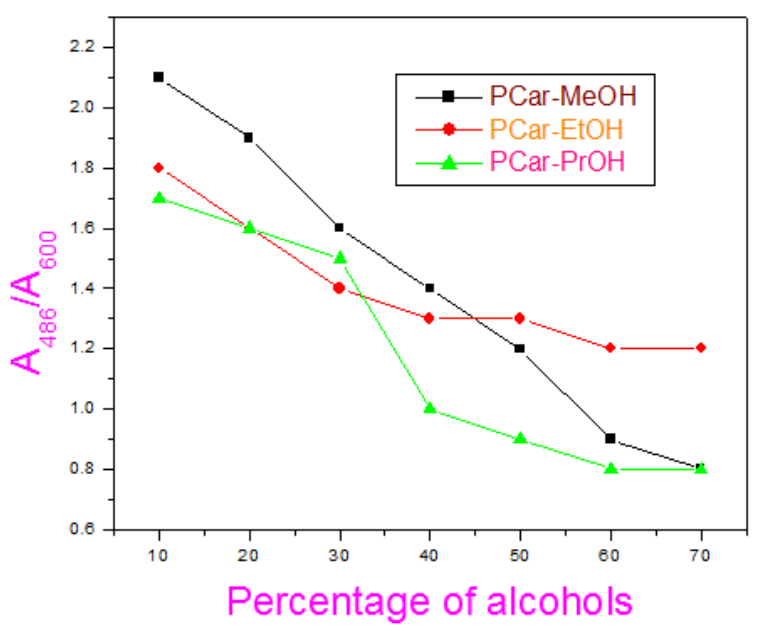

Figure 6. Reversal of metachromasy on addition of alcohols(Pcyn-NaCar)

The metachromatic effect is presumably due to the association of the dye molecules on binding with the polyanion which may involve both electrostatic and hydrophobic interactions. The destruction of metachromatic effect may occur on addition of low molecular weight electrolytes, alcohols or urea. The destruction of metachromasy by alcohol and urea is attributed to the involvement of hydrophobic bonding has already been established [45-49].The efficiency of alcohols in disrupting metachromasy was found to be in the order methanol<ethanol< 2- propanol, indicating that reversal becomes quicker with increasing hydrophobic character of the alcohols. The above facts are further confirmed in the present system .On addition of increasing amount of alcohol to the polymer/dye system at $\mathrm{P} / \mathrm{D}=2.0$, the original monomeric band of dye species is gradually restored. The efficiency of the alcohols, namely methanol, ethanol and 2propanol, on destruction of metachromasy were studied. In case of AB-NaCar system $45 \%$ methanol, $35 \%$ ethanol, $25 \%$ 2- Propanol were sufficient to reverse metachromasy $60 \%$ methanol, $50 \%$ ethanol, $40 \%$ 2- Propanol were required to reverse metachromasy in Pcyn- NaCar system. From the plot of $\mathrm{A}_{545} / \mathrm{A}_{645}$ or $\mathrm{A}_{486} / \mathrm{A}_{600}$ (Fig.5 and Fig.6) against the percentage of alcohols or molar concentration of urea, the percentage of alcohols or molar concentration of urea, needed for complete reversal has been determined. The concentration of urea to reverse metachromasy is found to be as high as $4.5 \mathrm{M}$ in AB-Car system and $5 \mathrm{M}$ in case of PcynNaCarsystem (Fig. 7 \& Fig. 8).This indicates that the metachromatic complex formed between Pcyn-NaCar is more stable than that between AB-NaCar complexes. Similar reports are available in literature for reversal of metachromasy in anionic polyelectrolyte/cationic systems by addition of alcohols or urea [50-51].

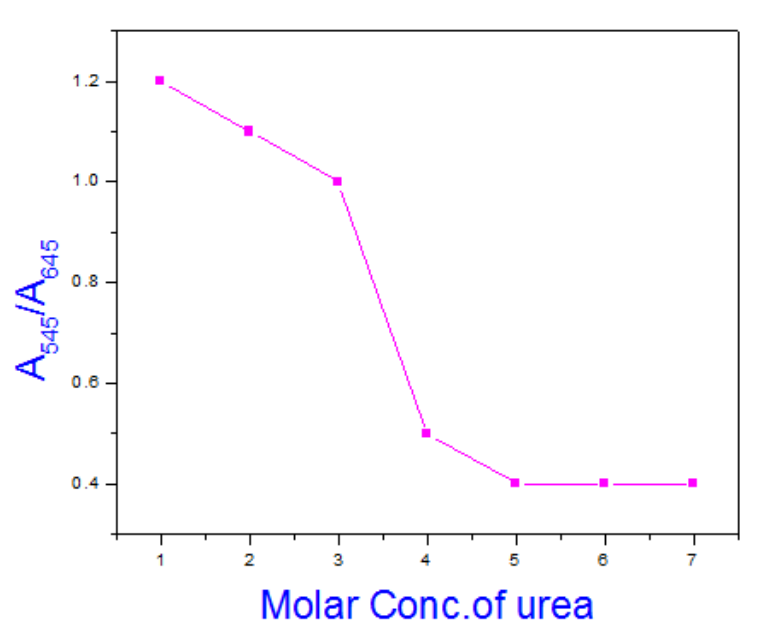

Figure 7. Reversal of metachromasy on addition of urea(AB-NaCar)

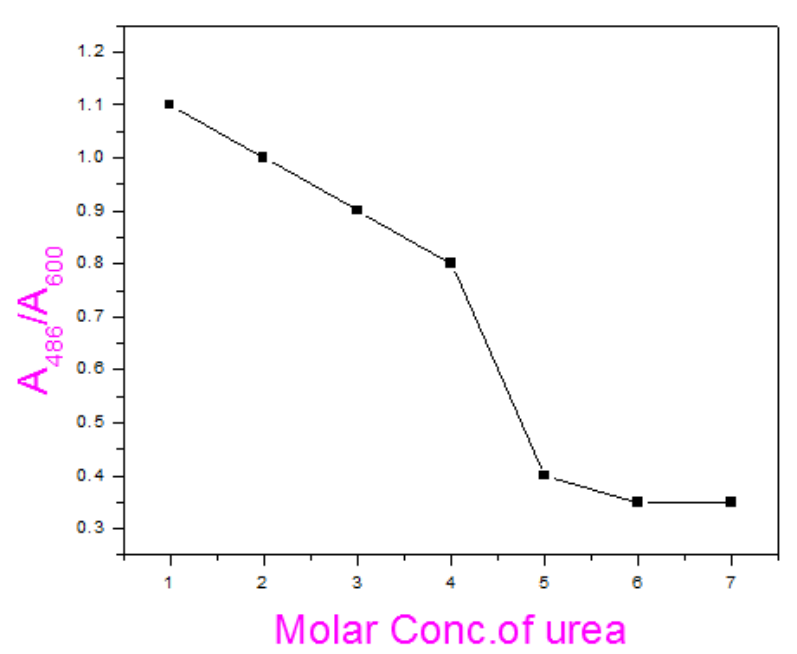

Figure 8. Reversal of metachromasy on addition of urea(Pcyn-NaCar)

\subsection{Reversal of Metachromasy Using Surfactants}

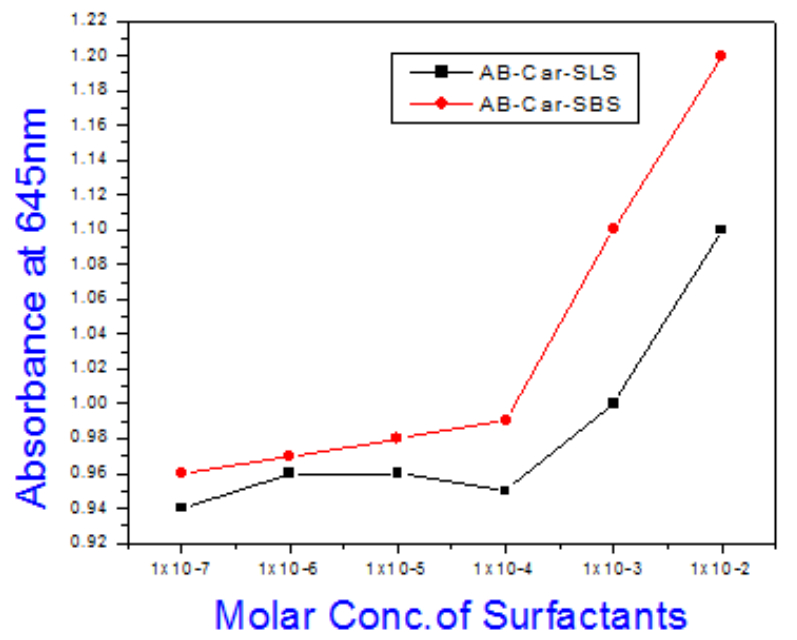

Figure 9. Reversal of metachromasy on addition of surfactants(AB-NaCar) 


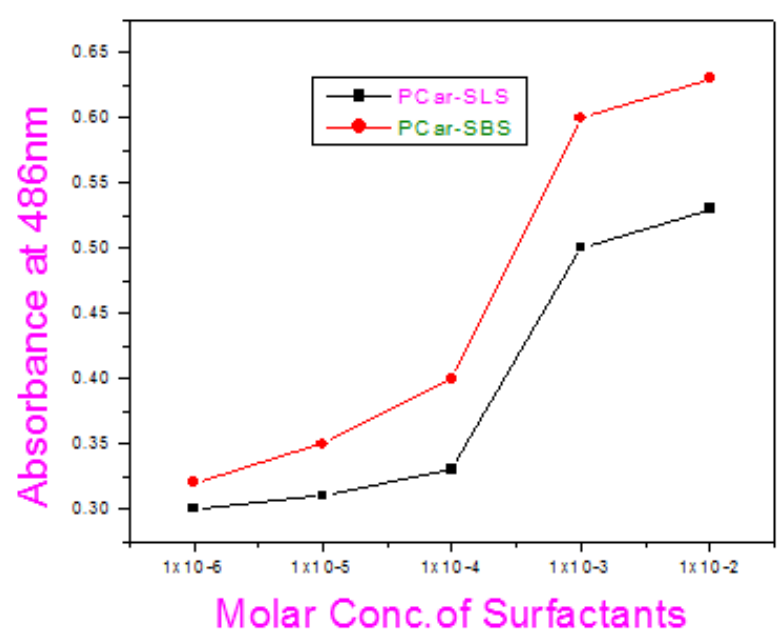

Figure 10. Reversal of metachromasy on addition of surfactants(PNaCar)

The strength and nature of interaction between water soluble polyelectrolytes and oppositely charged surfactants depend on the characteristic features of both the polyelectrolytes and the surfactants. The charge density, flexibility of the polyelectrolyte and the hydrophobicity of the non-polar part and the bulkiness of the polar part also play a vital role in the case of polysaccharide-surfactant interaction [52].On adding increasing amounts of sodium laurylsulphate and sodium dodecylbenzenesulphonate to ABNaCar complex the molar concentrations of Sodium laurylsulphate and Sodium dodecylbenzenesulphonate needed to cause reversal was found to be $1 \times 10^{-4} \mathrm{M}$ and $1 \times 10^{-}$ ${ }^{3} \mathrm{M}$ in case of $\mathrm{AB}-\mathrm{NaCar}$ and $1 \times 10^{-3} \mathrm{M}$ and $1 \times 10^{-2} \mathrm{M}$ in case of Pcyn-NaCar system. These results agree with those reported earlier in literature [53].Thus the addition of surfactants causes the production of micelles. Thus the surfactant molecules interacted with the polymer by replacing the cationic dye. The release of dye molecules from the dyepolymer complex in presence of cationic surfactants revealed that surfactants interacted electrostatically [54] with the anionic site of the polymer and thus the dye becomes free. The ease of reversal of metachromasy can be correlated with its chain length thus the binding between oppositely charged polymer surfactant is primarily by electrostatic forces which is reinforced by hydrophobic forces. From the plot of absorbance at $645 \mathrm{~nm}$ in case of Azure B or Absorbance at600 $\mathrm{nm}$ in case of Pinacyanol chloride against molar concentration of surfactants, the molar concentration of surfactants needed for complete reversal of metachromasy has been determined. The results are shown in (Fig. 9 and Fig. 10) respectively.

\subsection{Determination of Interaction Parameters}

The interaction constant $\mathrm{K}_{\mathrm{C}}$ for the complex formation between $\mathrm{AB}$ and $\mathrm{NaCar}$ and Pcyn-NaCar was determined by absorbance measurements at the metachromatic band at four different temperatures taking different sets of solutions containing varying amounts of polymer $\left(\mathrm{C}_{\mathrm{S}}\right)$ in a fixed volume of the dye solution $\left(C_{D}\right)$. The value of $\mathrm{Kc}$ was obtained from the slope and intercept of the plot of $\mathrm{C}_{\mathrm{D}} \mathrm{C}_{\mathrm{S}}$ / (A-
$\mathrm{A}_{\mathrm{O}}$ ) against $\mathrm{Cs}$ shown in Fig.11 \&Fig.12.

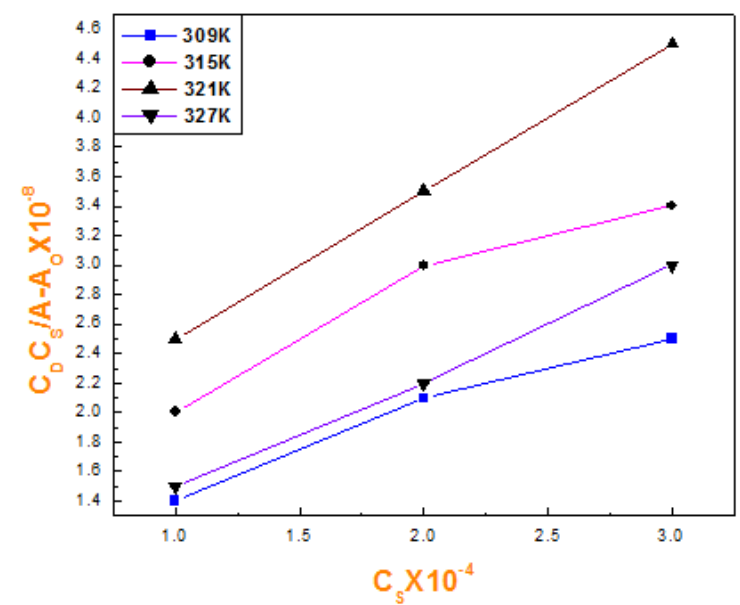

Figure 11. Effect of temperature on AB-NaCar system

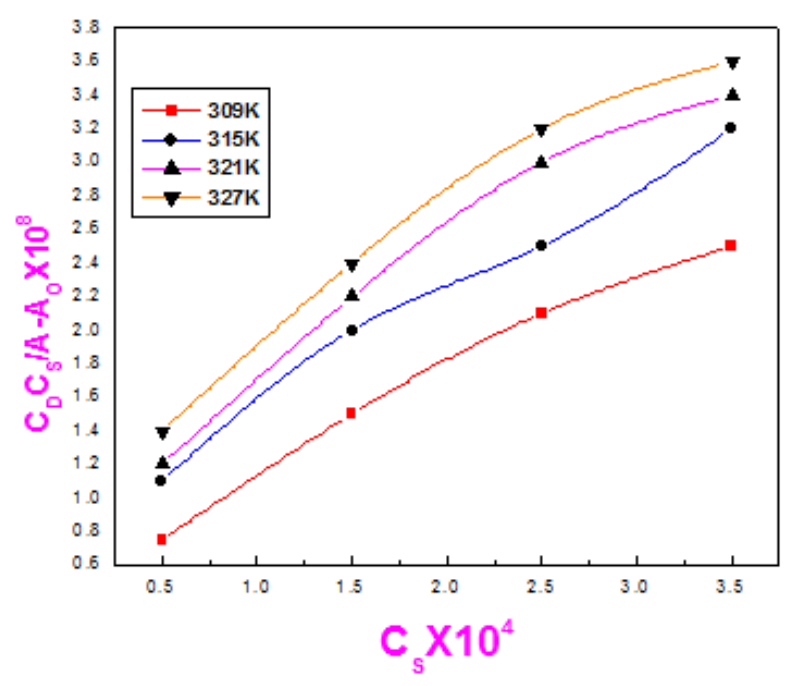

Figure 12. Effect of temperature on Pcyn-NaCar system

In each case the thermodynamic parameters of interaction, namely $\Delta H, \Delta \mathrm{G}$ and $\Delta \mathrm{S}$ were also calculated .The results are given in Table 1 and Table 2.

Table 1. Thermodynamic parameters of interactionfor Pcyn-NaCar

\begin{tabular}{lclll}
\hline Temp & $\mathbf{K C}$ & $\boldsymbol{\Delta G}$ & $\boldsymbol{\Delta} \mathbf{H}$ & $\boldsymbol{\Delta S}$ \\
\hline $309 \mathrm{~K}$ & 5400 & -4.156 & & \\
$315 \mathrm{~K}$ & 3500 & -4.577 & -2.4576 & -0.046 \\
$321 \mathrm{~K}$ & 2644 & -4.714 & & \\
$327 \mathrm{~K}$ & 1811 & -4.816 & & \\
\hline
\end{tabular}

Table 2. Thermodynamic parameters of interaction for AB-NaCar

\begin{tabular}{lllll}
\hline Temp & $\mathbf{K C}$ & $\boldsymbol{\Delta G}$ & $\boldsymbol{\Delta} \mathbf{H}$ & $\boldsymbol{\Delta S}$ \\
\hline $309 \mathrm{~K}$ & 7000 & -5.255 & & \\
$315 \mathrm{~K}$ & 2933 & -5.455 & -8.945 & -0.023 \\
$321 \mathrm{~K}$ & 1600 & -5.815 & & \\
$327 \mathrm{~K}$ & 1052 & -6.095 & & \\
\hline
\end{tabular}

a) Calculated from Fig .11. and Fig.12 according to RoseDrago equation 
b) Calculated from the thermodynamic equation $\Delta \mathrm{G}=-$ RTln Kc

c) Calculated graphically by plotting $\ln \mathrm{Kc}$ against $1 / \mathrm{T}$ according to Van't Hoff equation

$$
\ln \mathrm{Kc}=-\Delta \mathrm{H} / \mathrm{RT}+\mathrm{C}
$$

d) Calculated from the thermodynamic expression $\Delta \mathrm{G}=\Delta$ $\mathrm{H}-\mathrm{T} \Delta \mathrm{S}$

\subsection{Effect of Structure of Dye}

The structures of and Pinacyanol chloride and Azure B are given in (Fig. 13and Fig.14) respectively. It is evident that Azure B, being a rigid planar cationic dye and hence a small distance between the adjacent anionic sites on the polyanion will be more favorable for binding resulting in stacking arrangement, on the other hand Pinacyanolchloride being larger in size is more hydrophobic and hence induces greater aggregation. Thus in this case the distance between the two adjacent dye molecules will be greater and the dye molecules are oriented like a stair case which agrees with the reported literature $[55,56]$ Furthermore the dye molecules are arranged in a parallel and stacked manner within the aggregates resulting in a hypsochromic shift.

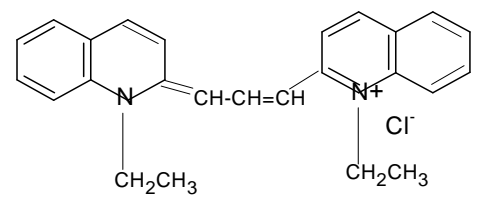

Figure 13. Structure of Pinacyanol chloride<smiles>CNc1ccc2nc3ccc(=[N+](C)C)cc-3sc2c1</smiles>

Figure 14. Structure of Azure B

\section{Conclusions}

The polymers sodium carrageenate induced metachromasy in the dye Azure B and Pinacyanol chloride. The monomeric band occurs at $645 \mathrm{~nm}$ and $600 \mathrm{~nm}$ while the metachromatic band occurred at $545 \mathrm{~nm}$ in the case of AB-NaCar and at 486 $\mathrm{nm}$ in the case of Pcyn-NaCar. The spectral shifts are higher in the case of Pcyn-NaCar $(114 \mathrm{~nm})$ than in case of AB$\mathrm{NaCar}(100 \mathrm{~nm})$. These results are further confirmed by the reversal studies using alcohols, urea, electrolytes and surfactants. The thermodynamic parameters further confirm the above fact. It is thus evident from the above studies that both electrostatic and non-ionic forces contribute towards the binding process. Based on the results it can be concluded that the Pinacyanol chloride is more effective in inducing metachromasy in sodium carrageenate than Azure B.Cooperativity in binding is observed to occur due to neighbour interactions among the bound dye molecules at lower P/D ratios leading to stacking. The stacking tendency is enhanced by the easy availability and close proximity of the charged sites.

\section{References}

[1] AMitra,R.KNath, SBiswas.,A.K., Chakraborty, A.K., Panda MitraA., J.Photochrem.Photobiol, A: Chem, vol.111, 1997, pp 157.

[2] A.Mitra, A.K.Chakraborty, J.Photochem.Photobiol.A:Chem., vol.178, 2006, pp198.

[3] R.W Horbin., Biochemie.Biochem., vol.77, 2002, pp 3.

[4] BergeronJ.A., M. J Singer, Biophys.Biochem.Cytol. vol.4,1958, pp.433.

[5] M.K.Pal ,B.K.Ghosh,Makromol.Chem.vol. 181,1980, pp1459 .

[6] Norden B., Kubista M., in: B.Samori, E.W.Thulstrup (Eds.), Polarized Spectroscopy ofordered systems, vol.242, Kulwer Academic Publisher, Dordrecht, Holland, 1988.

[7] Sabate R., EsterlichJ., J.Phys.ChemB, vol.107, 2003, pp.4137.

[8] von Berlepsch H., Kirstein S., Bottcher, C, Langmuir, vol.18, 2002, pp.769.

[9] Sabate R., Gallardo M., De la Maza A., J.Esterlich, Langmuir,vol.17,2001, pp.6433.

[10] Berret J.F., Cristobal G., Hervel P., Oberdisse J., Grillo I., vol.E9, Eur.Phys J 2002, pp.301.

[11] Meszaos R., Varga, I., Gilanyi T., J.Phys.Chem.B vol.117, 2005, pp.13538.

[12] Monteux C . ,WilliamsC.E., Meunier J., Anthony O., BergeronV., LangmuirVol.20,2004,pp. 57.

[13] Honda C., Kamizono H.,.Matsumoto K., Endo K., J.Colloid Interface Sci vol.278.2004, pp.310.

[14] MoulikS.P., GuptaS,.DasA.R., Makromol.Chem,vol.181, 1980,pp. 1459.

[15] Lee J., Moroi Y,,J.Colloid Interface Sci. 2 vol.273, 2004, pp.645.

[16] Mesa C.L., J.Colloid Interface Sci . vol.286, 2005, pp.148.

[17] Konradi R., Ruhe J., Macromolecules vol.38, 2005, pp.6140.

[18] VilletiM., BorsaliA., Crespo R., SoldiV., Fukada K., Macromol.Chem.Phys. vol.205, 2004, pp.907.

[19] Fundin J, Hansson P., Brown W., Lidegran I., Macromolecules vo.30, 1997, pp.1118.

[20] Mitra A., Nath A. R., and ChakrabortyA.K., Colloid Polym Sci. , vol.271,1993, pp.1042.

[21] Panda A.K., Chakraborty A.K., J.Colloid Interface Sci. vol.203,1998, pp.260.

[22] Chakraborty, A.K,.Nath, R.K, Spectrochim Acta vol.45A,1989, pp.981. 
[23] Jain N. , Trabelsi S., Guillot S., Meloughlin D. , Langevin D., Leteiller P., Turmine, M., Langmuir, vol..20,2004, pp.8496.

[24] Bakshi M.S., Varga I., GilanyiT., J.Phys.Chem.B, vol. 109, 2005, pp.13538.

[25] Balomenou L., and Bokias G., Langmuir, vol. 21,2005, pp.9038.

[26] Bakshi M.S., and Sachar S.,Colloid Polym.Sci. vol.283, 2005, pp.671.

[27] Romani A.P., Gehlen M.H., Itri R., Langmuir, vol.21,2005, pp.127.

[28] Wang C., Tam K.C., Langmuir, vol.18,2002, pp. 6484.

[29] Sjogren H ., Ericsson C.A., Evenas J., Ulvenlund S., Biophys $J .$, vol.89, 2005, pp.4219 .

[30] Zhu D.M., EvansR.K., Langmuir, 2006, 22, pp.3735.

[31] Chatterjee A., Moulik S.P., Majhi P.R., and Sanyal S.K., Biophys Chem.vol.98, 2002, 98, pp.313.

[32] Mata J., Patel J., Jain N., Ghosh G., Bahadu, P., J.Colloid Interface Sci. 2006, 297 , pp.797.

[33] Jiao Q.C., Liu Q., Sun C., and He H., Talanta, vol.1095,1999, pp.48.

[34] Liu Q., and Jiao Q.C ., Spectrosc.Lett., vol.31, 1998, pp.913.

[35] Jiao Q.C. and Liu Q., Spectrochim. Acta, 1vol.55A,999, pp.1667.

[36] Jiao Q.C and Liu Q., Anal.Lett. vol.31,1998, pp.1311.

[37] Jiao Q.C., and Liu Q, Spectrosc.Lett.vol.31, 1998, pp.1353.

[38] Hugglin D., Seiffert, A., Zimmerman, W, Histochemistry, vol.86,1986, pp.71.

[39] Mitra A., Nath R.K., and Chakraborty A.K., Colloid Polym. Sci., vol.271,1993, pp.1042.

[40] Basu. S., Gupta A.K., and Rohatgi-Mukherjee K.K, J.Indian
Chem. Soc.1vol.59,982, pp.578 .

[41] Pal M.K., SchubertM. J. Histochem Cytoche., vol.9,1961,pp. 673.

[42] Pal M.K,, and Ghosh B.K., Macromol.Chem, vol.181,1980, pp. 1459.

[43] Pal M.K and Ghosh B.K., Macromol.Chem. vol.180,1979, pp.959.

[44] Pal M.K and Schubert M ., J.Phys.Chem., vol.17,1963,pp.182.

[45] Frank. H.S., and Evans M.W., J.Chem.Phys. vol.17,1945, pp.507.

[46] Kauzmann W., Advan.Protein.Chem.vol.14, 1959, pp1.

[47] Bruning and Holtzer A., J.Am.Chem Soc.,vol.83,1961, pp. 4865 .

[48] WhitneyP.L., and Tanford C., J.Biol.Chem vol.237,1962, pp. 1735 .

[49] Mukerjee P., and Ray A. , J.Phys.Chem. vol.67,1963, pp.190.

[50] Frank H.S. and Quist A.S., J.Chem.Phys.,1 vol. 34, 961, pp.604.

[51] Rabinowitch E., Epstein., L.F J. Am. Chem. Soc., vol. 63, 1941, pp.69.

[52] Romani A.P., Gehlen M.H. and Itri R., Langmuir, vol.21,2005, pp.127.

[53] Levine A., Schubert M., J.Am.Chem.Soc., vol.74, 1958, pp.5702.

[54] Dasgupta S., Nath R.K., Biswas S., Hossain J., Mitra A., and Panda A.K., Colloids SurfA: Physicochem Eng.Aspects, vol.302, 2007, pp.17.

[55] RoseNJ; DragoRS; Journal of American Chemical Society, 1vol.81,959, pp.6138.

[56] Nandini R, Vishalakshi B, e-journal of chemistry, vol.8,2011, pp.S253. 